\title{
Using Web-Based Homework To Teach Principles Of Microeconomics: A Preliminary Investigation
}

Jeannette C. Mitchell, Ph.D., Rochester Institute of Technology, USA Johanna E. Mitchell, Ph.D., Hartwick College, USA

\begin{abstract}
This study evaluates an interactive web-based homework designed to increase student understanding in a principles of microeconomics course. Employing concepts from Action Research, the preliminary investigation was undertaken based on assumptions about the efficacy of online educational resources. Do students who do well on online homework improve performance on exams? Which characteristics of students explain achievement differences? The authors address these questions in relation to the use of a web-based, interactive online homework service which accompanied the text. An econometric model using exam performance as the dependent variable and various course component and demographic characteristics as independent variables. The study found no statistically significant impact of online homework on the mean exam score. This preliminary study indicated no gender, ethnicity, class standing, or declared major impact on exam performance though the limited degrees of freedom make generalization questionable. The only statistically significant predictor was shown to be GPA.
\end{abstract}

Keywords: Economics Education, Action Research, Web-Based Homework, Online Homework, Student Characteristics

\section{INTRODUCTION}

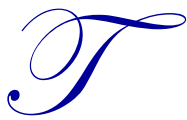

he economic situation in most institutions of higher learning has resulted in increased pressure by administrators to offer courses online in an effort to serve more students with less infra-structure (Kuzma et al., 2015). Many students who take online courses tend to view them as equally efficient as face-to-face courses, although Estalimi (2015) has shown that students who view these courses as more efficient than traditional courses tend to have a weaker academic profile and lower grade expectations. Nonetheless, online course offerings are very attractive to administrators pressured to do more with less. Faculty, however, consider online courses a mixed blessing. Peng $(2009,263)$ properly noted that there seems to be a "hidden assumption" that the mere introduction of technology into the classroom somehow improves outcomes and that this “...assumption... receives little or no challenge from educators." Grossman and Johnson (2015) have demonstrated that faculty members tend to consider online courses less demanding of students and less proficient at instilling some skills than face-to-face courses. Yet, the emphasis placed on online course offerings continues. Indeed, this effort has been accompanied by a growing emphasis on using technology-based assignments and techno-strategies in face-to-face college courses. Web-based homework packages frequently accompany introductory textbooks on the assumption that online learning may be one solution to educational challenges experienced by contemporary college students. It is sometimes assumed that online learning and other technological innovations in teaching strategies augment student comprehension of content and success with course requirements.

That homework can positively impact student learning at the secondary and post-secondary levels seems intuitively obvious. It seems to be common knowledge among educators that students who engage with homework assignments, do the reading, and take notes on the reading will obviously learn more. Indeed, the perception of homework as a tool to augment learning is frequently espoused. Following the issuance of A Nation at Risk in 1983, homework has been encouraged and often required at the elementary and secondary levels based on the view that it will serve to increase achievement levels on standardized tests (Hadden, 2003). The problem for many instructors at 
the college and university levels with using homework, however, is the instructor's time commitment involved. To be effective, homework needs to be directly tied into lectures and other assignments, graded promptly, and must include extensive comments and written teaching points. Homework could be encouraged and not graded, but anecdotal evidence suggests that students do not have the intrinsic motivation to commit the time without the concomitant extrinsic motivation of a grade.

A web-based homework approach addresses both the time commitment and student extrinsic motivation problems. The only instructor time involved is the creation of the assignments. Many established web-based programs exist with hundreds of questions from which to choose. There may be a greater time commitment if the text does not cover the same material or cover it in the same way. The convenience of web-based homework lies in the fact that most programs grade and record scores. Students receive immediate feedback and the program provides elaborate supporting comments. Students may also opt to focus on weaknesses by using a feature of the software to develop individualized study guides.

Studies have demonstrated that, in general, the format of homework makes no achievement difference. In a study of mathematics students using web-based homework and students using paper-and-pencil homework, Lenz (2010) found no statistically significant difference. Aberson, Berger, Healy and Romero (2000) reported comparable results between the use of web-based tutorials and traditional lecture/demonstration approaches in teaching the Central Limit Theorem. In the study of teaching of hypothesis testing along similar lines, Aberson, Healy, Berger and Romero (2000) confirmed no difference in learning outcomes between web-based tutorials and other forms of homework. A study by Alexander, et al. found no statistical difference between performance on exams given in paper form or online. Studies in disciplines other than statistics bear these findings out (Bliwise 2005; Demirici 2010; Dufresne, Mestre, Hart and Rath 2002). Similarly, Self (2015) found that although online learning tools did not by themselves improve student performance, voluntary involvement, as demonstrated by student access to additional materials available in the program, did. Flannery, et al. (2013) found that paper assignments can better prepare students for end of term written exams than online systems. They did find that online had a better completion rate and students using it did have some improvement on some aspects of exams. Similarly, Olitsky and Cosgrove (2014) found that blended courses did not significantly improve outcomes as compared with a traditional classroom setting.

As the literature generally agrees that there is no difference in impact on achievement as between traditional homework and web-based homework, we decided to investigate the extent to which a web-based homework impacted student exam performance. We employed methods reflective of action research because, as Punch (1994) has shown, action research methods repudiate deceptive measures that do not view subjects as stakeholders. Our students' grades would, we believe, be impacted by the use of the web-based homework; and, action inquiry has been referred to by Denzin and Lincoln (1994) as one of the most humanistic of the traditions in qualitative research because of the holistic and relevant nature of the research. We expected that the web-based homework assignments would have a positive and significant impact on exam grades and would, therefore, be a useful addition to the course.

Despite the growing availability of computer based teaching aides, Becker and Watts (2001) found that economists generally prefer the "talk and chalk" format for their teaching. A possible explanation is provided by Harter and Harter (2004) who found no significant improvement in student scores on the final exam with the use of course webpages and on-line quizzes when other student characteristics were taken into account. Harter and Harter concluded that pre-course abilities, such as GPA, were a much better predictor of student performance than access to on-line resources and quizzes. The current work contributes to the literature by including the impact of online homework assignments on mean exam scores.

Janesick (1994) argues that action researchers who study their own teaching practice accept the fact that their research is ideologically-driven. They acknowledge that there is no value free research and admit early on in any study that the researchers themselves as well as their subjects have biases. In accordance with the principles of action research and along with the expectation that doing the homework would increase student grades on exams, we entered this preliminary examination with other preconceived notions. We believed that other factors would also impact achievement. Since the course was an economics course, we thought that gender would be a variable that 
would impact achievement but that ethnicity would not. We also believed that GPA, class standing, and declared major would influence achievement on the exams. We decided to conduct this study as a preliminary one, to eventually be followed up in later semesters with participant interviews, video taped sessions, and student evaluations. The ultimate goal was to employ technology in a group work format so that the actual teaching practice in the economics course may be augmented and would ultimately increase student interest and achievement in the content covered.

Watts and Becker (2008) found an apparent reluctance on the part of academic economists to employ technological innovations in their classrooms and postulate that there has not been sufficient incentive for economists to alter their teaching. Chalk and talk methods remain the preferred mode of teaching in most economics courses nationwide. However, incentives to include technological innovations do exist in our institutions. Faculty salary increments, tenure, and promotion decisions are based on performance in teaching, scholarship and service. Innovation in teaching has increasingly been identified as incorporating technology into course design. Faculty are encouraged to Learning Management Systems such as "Mycourses" and "Blackboard." Universities have also encouraged faculty to utilize the internet and power-points by equipping classrooms with the hardware necessary to do so.

For the current study, web-based homework assignments were introduced to a Principles of Microeconomics class. The intent of the study was to test and quantify the favorable impacts of online homework assignments when other student characteristics are taken into account. The questions were chosen from a test bank containing hundreds of options with the objective of increasing student understanding in order to improve essay-based test performance. Students were required to complete ten web-based homework assignments, one per week. The questions were largely multiple choice but some included calculations and point-and-click graphical techniques. All course materials were prepared and graded by the same instructor.

Table 1. Course Requirements

\begin{tabular}{l|c|l}
\hline \multicolumn{1}{c}{ Course Requirements } & \%Grade & \multicolumn{1}{c}{ Number Of Assignments } \\
\hline Examinations & 65 & 3 equally weighted unit exams \\
\hline Online Homework & 10 & 10 equally weighted assignments \\
\hline Take Home Quizzes & 25 & 5 equally weighted assignments \\
\hline
\end{tabular}

The other course requirements included three essay and calculation based unit tests and completion of 5 of 10 assigned take-home quizzes. The exams had 4 to 5 questions which generally required students to graphically illustrate a central concept or carry out some computations and to provide an intuitive explanation of the concept. The take-home quizzes characteristically involved one question with data manipulation and two short essay questions where students were asked to summarize and evaluate short current event articles written by economists. Ten quizzes were made available and students chose 5 to complete and submit for grading. Take-home quizzes accounted for $25 \%$ of the final grade. The remaining 10 percent of the course grade was determined by performance on the web-based homework assignments.

An access code to the web-based homework came bundled with the text. There were ten homework assignments created. The questions were chapter-based, generally multiple-choice with students given two chances to identify the correct response. If the student chose an incorrect response, the program explained why the answer was incorrect and strongly hinted at the correct choice. If a correct response were given, the next question appeared. These homework assignments ranged in length from 10 questions to 30 and students had access to the homework for an entire week. The program also allowed students to design their own study guides with additional practice questions. The web-based tutorial homework provided immediate feedback as well as opportunities for further engagement.

Table 2. Descriptive Statistics

\begin{tabular}{l|c|c|c|c|c|c|c|c|}
\hline & Exams & Quizzes & Homework & GPA & Hours & Male & Engineers & White \\
\hline Mean & 48.01 & 74.98 & 83.11 & 2.91 & 61.34 & & \\
\hline Number & & & & & & 36 & 8 \\
\hline
\end{tabular}


The study looked at whether the web-based homework had a positive and significant impact on student exam performance. The independent variable was the mean exam grade the independent variables included the web-based homework grade as a percent (HOMEWORK), the take-home quiz grade (QUIZ) as a percent, the student's GPA before taking Principles of Microeconomics, the credit hours completed by the student at before taking the Principles of Microeconomic course (HOURS) and three demographic variables designed to capture the importance of gender (MALE), ethnicity (ETHNICITY) and major (MAJOR).

Table 3. Regression Results

\begin{tabular}{|c|c|c|}
\hline Parameter & Coefficient & p-value \\
\hline Constant & -21.390 & 0.184 \\
\hline Homework & 0.295 & 0.229 \\
\hline Quiz & 0.066 & 0.639 \\
\hline Gpa & 14.169 & 0.006 \\
\hline Hours & -0.086 & 0.156 \\
\hline Male & 1.923 & 0.766 \\
\hline Ethnicity & 3.786 & 0.505 \\
\hline Major & -0.070 & 0.992 \\
\hline
\end{tabular}

Our expectation was that the homework parameter, the mean homework score, would be positive and highly significant. Homework questions were chosen with the intent of improving exam performance. It was also expected because on both the first and second exams a homework question was reviewed during the exam review session and then included on the exam. To our surprise, the homework coefficient proved statistically insignificant.

The take-home quizzes were made visible every Thursday of the quarter and due the following Thursday. Students had exposure to 10 quizzes and had to complete five. They were also given the option of having the instructor review the quiz review before submitting for credit, though few students took advantage of that offer. The quiz assignments asked students to read short news articles ( 3 per quiz) written by economists and to critically summarize and analyze the arguments of the economists given the student's understanding of theory to that point. Quizzes usually included a pure theory or calculation aspect. For example, on the third quiz students were asked to calculate and interpret an elasticity value. The QUIZ coefficient was also statistically insignificant. We were not surprised by this result as the quizzes were designed primarily to enrich and broaden students and not designed to improve exam performance, per se.

Student GPAs ranged from a low of 1.3 to a high of 4.0 and mean GPA of 2.91. As the course was taught during the Spring Quarter there were no students that participated in the study that were in their first quarter. GPA was the only statistically significant coefficient. It seems to reason that students that do quality work in general, as represented by the high GPA, would also do quality work in economics. Our results are consistent with what Dotterweich and Rochelle (2012) reported in an earlier edition of this journal. Dotterweich and Rochelle looked at three different delivery methods; online, Instructional TV, and a traditional classroom, in order to determine if the type of delivery impacted student performance. Their study found that only GPA and the percent of absences were found to be statistically important.

The HOURS variable was the number of hours completed by the student prior to enrolling in economics. We expected that students with more hours of college study would perform better than those with less experience in college. Again we were surprised to find that hours completed was an insignificant predictor of exam performance. It has been demonstrated that, in general, females tend to perform less well than males in economics (Soper and Walstad 1988; Walstad and Robson 1997). In the present study, the gender variable (MALE) was represented by a dummy with Males equal to one and females equal to zero. Given the findings of Soper and Walstad (1988) we expected females to perform less well. In this case the gender variable was statistically insignificant. The Ethnicity variable was based on self-reporting by the students and because of the small sample size had to be broken into a bivariate dummy variable of white/non-Hispanic and everyone else. Two-thirds of the students in this study were white/non-Hispanic. Ethnicity proved statistically insignificant contrary to the findings of others in the field (Soper 
and Walstad1988) but the results of the current preliminary study are definitely called into question because of the small sample and subsample sizes.

A dummy variable approach was also used for MAJOR. Major was stipulated as a 1 for students from the College of Engineering and 0 for students who majored in non-engineering fields. There were eight engineers and 15 were majoring in computer science or software design. Based on the findings of Bosshardt and Watts' 2008 Journal of Economic Education study we expected engineers to perform better, on average, than their counterparts in other majors. In the present work the major (engineers) was statistically insignificant.

\section{CONCLUSION}

That homework can positively impact student learning at the secondary and post-secondary levels seems intuitively obvious. In this study we fully anticipated that web-based homework assignments would have a favorable impact on student exam grades. Our ultimate intention was to eventually employ more action research principles and practices in order to augment student achievement and interest in the principles of economics course content. We hoped to ultimately add group work and steer further away from the emphasis on the chalk and talk method of teaching the course. However, this study demonstrates that, in this case, the web-based homework assignments did not have a significant impact on student exam grades when other student characteristics were included. Indeed, GPA was the only statistically significant variable leading us to conclude that students who get high grades in other courses, should be expected to fare well in economics.

There are several possible explanations of this counter-intuitive outcome as a result of the design of the experiment. One possible explanation of the result is related to homework design. Poor question choice could be the reason for no demonstrable impact. Perhaps the questions on the web-based homework did not correctly reflect concepts asked for on the examination. After the results of the OLS were obtained we again reviewed the homework and exam questions and feel confident that the design to improve exam performance was sound. It could be that the multiple choice format of the web-based homework did not help students with the essay based examinations. But as two of the homework questions (cumulatively worth more than 15 percent of the exam grade) appeared on exams after being discussed in a review session, this explanation seems unsatisfactory.

Another explanation of the counterintuitive result is that multiple choice questions tend to "...encourage guessing" (Walstad and Becker1994). Most of the multiple choice questions had four possible answers. Just guessing would give students a 25 percent chance of getting it correct the first time. If the student misses it the first time, the odds increases substantially on getting the question correct the second time. The chance increases more than just to one out of three as the program hints strongly as to the correct answer if the student chooses incorrectly the first time.

As we consider future research in this area, we hope to add elements of action research programs that employ the study as a piece of what Smith (1994) has referred to as teacher autobiography. We hope to include, then, more personal context, larger chunks of autobiography through journals and reflections, and work with our students as partners in the study in order to enhance our practice as researchers and especially teachers. Since our ultimate goal is to improve our own teaching and to reveal those methods which work best to increase student achievement, studying and critiquing our own practice as teachers is essential.

Future research will also look to redress the small number of observations in this study as well as to add aspects of action research that involve students more as stakeholders and participants in the study. In addition, we hope to reduce the probability of guessing correctly in order to estimate better the impact of the web-based homework. It may be the case that economics instructors shy away from using more technology less because of some Ludditebased tendencies and more that they have a general understanding that using more technology does not automatically translate into superior results. The results of this preliminary study have caused us to re-evaluate not only the homework assignments, the formats of the homework and exams, as well as the questions. The results cause us to question the efficacy of web-based learning situations and other individualized approaches to learning in relation to methods that emphasize relationship-building through shared work (students and faculty, students and students, learners and teachers) over course curricula. 


\section{AUTHOR BIOGRAPHIES}

Jeannette Mitchell is Associate Professor of Economics at the Rochester Institute of Technology. Her specialties include International Trade and Finance and History of Economic Thought. She has teaching experience in Econometrics, Economic Forecasting, and Mathematical Economics, among others. Administrative experience includes serving as Center Director for the RIT Economic Education Center (1994-2000) and Undergraduate Program Director (2014-present). Current interests include economic education and history of economic policy. Email: jcmgsm@rit.edu (corresponding author)

Johanna Mitchell is Associate Professor of Education at Hartwick College. Her specialties include Elementary Science and Mathematics Methods, Secondary Social Studies, History of Education, and Education Policy. She has extensive K-12 education experience as well as experience at the university level. Current interests include the industrial revolution and its impact on the literature of the period. E-mail: mitchellj@hartwick.edu

\section{REFERENCES}

Aberson, C.L., Berger, D.E., Healy, M.R., Kyle, D.J., and Romero, V.L. (2000). Evaluation of an interactive tutorial for teaching the central limit theorem. Teaching of Psychology, 27(4) 289-291.

Aberson, C.L., Berger, D.E., Healy, M.R., and Romero, V.L. (2003). Evaluation of an interactive tutorial for teaching hypothesis testing concepts. Teaching of Psychology 30(1) 75-78.

Alexander, M., Bartlett, J., Truell, A., and Ouwenga, K. (2001). Testing in a computer technology course: An investigation of equivalency in performance between online and paper and pencil methods. Journal of Career and Technical Education. 18(1) 69-80.

Becker, W. E., and M. Watts. (2001). Teaching methods in U.S. undergraduate economics courses. Journal of Economic Education, 32 269-79.

Bliwise, N.G. (2005). Web-based tutorials for teaching introductory statistics. Journal of Educational Computing Research, 33(3) 309-325.

Demirci, N. (2010). The effect of web-based homework on university students' physics achievements. Turkish Online Journal of Educational Technology, 9(4) 156-161.

Denzin, N.K. (1994). Handbook of Qualitative Research. (Thousand Oaks, CA: Sage).

Dotterweich, D. and Rochelle C. (2012). Online, instructional television and traditional delivery: Student characteristics and success factors in business statistics. American Journal of Business Education, 5(2) 129-137.

Dufresne, R., Mestre, J., Hart, D.M. and Rath, K.A. (2002). The effect of web-based homework on test performance in large enrollment introductory physics courses. Journal of Computers in Mathematics and Science Teaching, 21(3) 229-249.

Estelami, H. (2016) An exploratory study of the effects of online course efficiency perceptions on student evaluation of teaching (SET) measures. American Journal of Business Education, 9 (2) 67-81.

Flannery, D., Kennelly, B., and Considine, J. Paper and online assignments in economics: A comparison with panel data, International Review of Economics Education, 13, 31-43.

Grossman, A.M., and Johnson, L.R. (2015) Faculty perceptions of online accounting coursework. American Journal of Business Education, 8 (2) 95-105.

Hadden, J. E. (2003). The power structure behind educational policy: The 1983 reports. University of Utah doctoral dissertation.

Harter, C.E., and Harter, J.F.R. (2004).Teaching with technology: Does access to computer technology increase student achievement? Eastern Economic Journal, 32(4) 507-514.

Janesick, V.J. (1994). The dance of qualitative research design: Metaphor, methodology, and meaning. Handbook of Qualitative Research. Norman K. Denzin and Yvonna S. Lincoln (eds). 209-219.

Kuzma, A., Kuzma, J. and Thiewes, H. (2015). Business student attitudes, experience, and satisfaction with online courses. American Journal of Business Education, 8 (2) 121-129.

Lenz, Laurie. (2010). The effect of a web-based homework system on student outcomes in a first-year mathematics course. Journal of Computers in Mathematics and Science Teaching, 29(3) 233-246.

Olitsky, N.H. and Cosgrove, S.B. (2014) The effect of blended courses on student learning: Evidence from introductory economics courses, International Review of Economics Education, 15, 17-31.

Peng, J. (2009). Using an online homework system to submit accounting homework: Role of cognitive need, computer efficacy, and perception. Journal of Education for Business, May/June 2009, 263-268.

Punch, M. (1995). Politics and ethics in qualitative research. Handbook of Qualitative Research, Norman K. Denzin and Yvonna S. Lincoln (eds). 83-97.

Self, S. (2015) Utilizing online tools to measure effort: Does it really improve student outcome? International Review of Economics Education, 14, 36-45.

Smith, L. (1994). Biographical method. Handbook of Qualitative Research, Norman K. Denzin and Yvonna S. Lincoln (eds). 
286-305.

Soper, J.C. and Walstad, W.B. (1988). What is high school economics?: Posttest knowledge, attitudes and course content. Journal of Economic Education, 19(1) 37-51.

Walstad, W.B. and Becker, W.E. (1994). Achievement differences on multiple-choice and essay tests in economics. American Economic Review, 84(2) 193-196.

Walstad, W.B. and Robson, D. (1997). Differential item functioning and male-female differences on multiple choice tests in economics. Journal of Economic Education, 28(2) 155-171.

Watts, M. and Becker, W.E. (2008). A little more than chalk and talk: Results from a third National Survey of Teaching Methods in Undergraduate Economics Courses. Journal of Economic Education, 39(3) 273-286. 


\section{NOTES}

